\title{
Saprotrophs and nitrifiers, not pathogens, drive plant-soil feedbacks in a semi-arid grassland
}

\author{
Pierre-Luc Chagnon ${ }^{1}$, Charlotte Brown ${ }^{2}$, and James Cahill ${ }^{2}$ \\ ${ }^{1}$ Université de Montréal \\ ${ }^{2}$ University of Alberta
}

August 27, 2020

\begin{abstract}
By influencing soil biota and nutrient cycling, plants can alter their fitness and that of their neighbours through plant-soil feedbacks. However, we need more detailed understanding of the biological causes of such feedbacks. This includes identifying the soil microbial guilds causing them. As most plant-soil feedbacks have been reported to be negative, the dominant paradigm is focused on the accumulation of soil pathogens. This neglects the full range of soil microorganisms likely to influence plant performance. Here, we studied plant growth responses to field-collected soil inocula in a large-scale greenhouse study coupled with next-generation sequencing. Although we found a high prevalence of negative plant-soil feedbacks, the microorganisms driving the responses were largely saprotrophs and N-cycling prokaryotes, not pathogens. These results show that negative plant-soil feedbacks need not be caused by trophic interactions, highlighting the need to bring back nutrient cycling as a central component of plant-soil feedbacks.
\end{abstract}

\section{Introduction}

Plants modify the soil they grow in, be it through taking up nutrients (Fireman \& Hayward, 1952; Zinke, 1962), returning litter of varying chemical quality thereby impacting nutrient cycling (e.g., Wedin \& Tilman, 1990; Hobbie, 1992), or accumulating specific soil organisms in their rhizosphere (Bever et al. , 2010). This, in turn, influences their success through plant-soil feedbacks (PSF) (van der Puttenet al. , 2013). In the 1980's and the 1990's, most attention has been paid to PSF driven by abiotic nutrient dynamics (e.g., Chapin, 1980, 1991; Tilman, 1980; Chapin et al. , 1986; Horner et al. , 1988; Kuiters, 1990). Correlations have been observed between nutrient use efficiency and litter chemical quality, such that plants from nutrient-poor environments tend to favor their own success (i.e., experience positive PSF) by producing a recalcitrant litter (Berendse, 1994; Bryant et al. , 1991), which slows down nutrient cycling and increase their competitive ability (Wedin \& Tilman, 1990). However, seminal work showing implications for soil-borne disease in sand dune succession (van der Putten et al. , 1993) has prompted a shift of focus towards a role for pathogens in driving plant community structure (e.g., Dobson \& Crawley, 1994; Thrall et al. , 1997). This still transpires in more recent views of PSF not being driven by litter chemistry, but by the accumulation of specific soil biota, emphasizing pathogens (e.g., Klironomos, 2002; Bauer et al. , 2015; Beveret al. , 2015; Albornoz et al. , 2017).

Plants accumulate a variety of organisms in their rhizosphere (e.g., bacteria, fungi, nematodes) ranging from harmful to beneficial. Because the bulk of measured PSF tend to be negative (Kulmatiski et al. , 2008), many have proposed PSF as a mechanism promoting plant coexistence through enemy accumulation by dominants (Olff et al. , 2000; Mangan et al. , 2010; Reinhart, 2012). As a result, a disproportionate amount of research has focused around pathogen accumulation in the rhizosphere (e.g., Mills \& Bever, 1998; Manganet al. ,2010; Bagchi et al. , 2010,2014; Sarmiento et al. , 2017). Pathogens have been suggested to explain the underyielding of low-diversity plots in plant diversity experiments (Schnitzeret al. , 2011; de 
Kroon et al. , 2012; van Ruijven et al. , 2020), and the negative density dependence of plant growth in a variety of environments (e.g., old fields: Klironomos, 2002; shrublands: Laliberté et al. , 2015; temperate forests: Packer \& Clay, 2000; tropical forests: Mangan et al. , 2010). However, negative feedbacks need not be caused by enemies (Bever et al. , 1997; Bever, 1999). Indeed, the accumulation of less efficient microbial mutualists (Bever, 2002) or of microbial competitors (Hodge et al. , 2000) can also make a plant grow better in heterospecific vs conspecific soil, leading to negative PSF even in the absence of pathogens. Likewise, positive PSF have often been ascribed to mutualistic symbionts (e.g., Klironomos, 2002; Revillini et al. , 2016), ignoring the variety of soil biota guilds that can generate positive PSFs. For example, although plants can grow better in a soil with specific symbiotic partners (e.g., mycorrhizal fungi), they can also positively respond to the presence of specific microorganisms that (1) better cycle/solubilize nutrients (Marschner et al. , 2011), (2) are less efficient competitors for mineral nutrients (Hodge et al. , 2000), or (3) are less virulent pathogens (Agrios, 2005; Dominguez-Begines et al. , 2020). Yet, very few studies have specifically addressed the role for non-symbiotic and non-mutualistic organisms in driving positive PSF (Yang et al., 2013).

While there is a need to identify the full spectrum of microbial taxa/guilds that drive PSF, this could be hampered by the tremendous diversity of the soil microbiome. The rhizosphere of a single plant individual can easily be colonized by thousands of microbial taxa (Wanget al. , 2018), which could make it hard to identify individual microbial taxa driving PSF. One way forward could be to directly correlate PSF to soil microbial $\alpha$-diversity or community structure, regardless of individual microbial taxa and their guild affiliation. However, while many have argued that plant performance could be tied to the diversity of their microbiome (van der Heijden et al. , 1998; Laforest-Lapointe et al. , 2017), a higher diversity also opens the way to more complex indirect interactions among microorganisms (Hector et al. , 2010), with PSF potentially being simply more complex and unpredictable, not more positive (e.g., Tardif \& Shipley, 2015). It thus remains unsure whether community-level properties of the microbiome can be of any help to simplify PSF predictions.

Another key knowledge gap in PSF theory is to determine how PSF-driving microorganisms respond to environmental filters. A pivotal assumption of PSF as key drivers of plant and microbial community assembly is that the microorganisms influencing plant performance must be responsive to plant community structure (Bever et al. , 1997). Yet, many studies have identified soil abiotic properties as the core drivers of soil microbiome (e.g., Dumbrell et al. , 2010). If this is true for microorganisms influencing plant growth, this means that pot-based PSF, where soil chemistry is kept homogeneous while plant identity is manipulated, may have limited ecological relevance. Also, if the wide array of microorganisms causing PSF all respond differently to environmental filters, predicting PSF along ecological gradients (e.g., Smith-Ramesh \& Reynolds, 2017; Bennett \& Klironomos, 2018) will be challenging. For example, fertile soils may promote higher plant density and dominance by a few competitive species (Fraser et al. , 2015), conditions that would promote pathogen accumulation and negative PSF (Thrall et al. , 2007). On the other hand, high soil fertility could also relieve plants from microbial competitors for nutrients (e.g., Liu et al. , 2016), which may rather lead to positive PSF. The high soil microbial diversity appears again as an obstacle towards a mechanistic understanding of PSF.

In this study, we aimed at providing a more comprehensive explanation for PSF observed in a grassland ecosystem, focusing on the growth responses of two abundant C3 grasses: Koeleria macrantha (Ledeb.) Schult and Bromus inermis Leyss. Building on a previous greenhouse experiment where we measured Bromus and Koeleria growth responses to 490 soil inocula collected in the field (Chagnon et al. , 2018), here we characterized the soil microbiome from a large subset of these inocula. This allowed us to identify the microbial taxa that best correlate with altered plant performance (i.e., non-neutral PSF), and answer the following questions:

1. Are negative PSF driven largely by microbial pathogens or due to other microbial guilds?

2. Can plant growth response to soil inocula be predicted based on microbial $\alpha$-diversity or community structure?

3. Are microorganisms causing PSF more correlated with gradients in plant community structure than 
with proximate soil properties?

Material and methods

Study site description, sampling design and plant growth response measurement

During summer 2015 we conducted a field study at the University of Alberta's Mattheis Ranch, located in southern Alberta and at the northern edge of the Great Plains $\left(50^{\circ} 53^{\prime} 29.9^{\prime \prime} \mathrm{N} 111 \mathrm{deg} 55^{\prime} 07.4^{\prime \prime} \mathrm{W}\right)$. The vegetation was a semi-arid mixed grassland dominated by Koeleria macrantha (Ledeb.) Schult, Hesperostipa comata (Trin. \& Rupr.) Barkworth, Pascopyron smithii (Rydb.) A Love and Bromus inermis Leyss. (Shorthouse, 2010).

To evaluate plant-soil feedbacks in this system, we sampled 49 10-cm-diameter soil cores in 10 different plots, for a total of 490 soil samples. Details on the soil sampling methods can be found in Chagnonet al. (2018). These soils were used as living inocula in a greenhouse experiment, where Bromus or Koeleria were grown in a 9:1 mixture of sterile soil and living inoculum. The sterile soil consisted of a 1:1 mixture of a sandy soil collected at our study site, and fine sand. Using such a design, any growth response by Bromusor Koeleria was expected to be caused largely by soil biota (Brinkman et al. , 2010). After 15 weeks of growth, plants were harvested and total (shoot + root) dry mass was used as a measure of plant growth response to soil inocula (i.e., PSF). The remaining methods described below are new to this paper, and were not part of the original publication (Chagnon et al. , 2018).

To identify soil microorganisms potentially generating plant growth responses in our experiment, we combined the data generated from the previously described greenhouse experiment with targeted soil DNA sequencing. Of our 490 initial soil living inocula, we selected 230 inocula that would also be analyzed for microbial community structure, representing 23 samples in each of our 10 plots. The 23 inocula were chosen in a way that maximized their spatial dispersion in all four quadrants of the plot (Fig. S1). The field soil subsamples had been kept at -20C until DNA extraction, which was within 2 months after soil collection.

\section{Molecular analyses}

Soil DNA was extracted using MoBio PowerSoil kits (r) following manufacturer's instructions. Prokaryotic and fungal DNA were amplified targeting the 16S and ITS rDNA regions, respectively. The primers used for the amplification were the 515f-806R couple (targeting the hypervariable V4 region) for $16 \mathrm{~S}$ and the ITS1fITS2 couple for ITS (targeting the ITS1 subregion) (White et al. , 1990; Gardes \& Bruns, 1993; Gilbert et al. , 2014). PCR amplifications were conducted with $0.2 \mu \mathrm{M}$ primers, $0.2 \mathrm{mM}$ dNTPs, 0.5 units of hi-fidelity Taq polymerase (New England Biolabs), and $1 \mu \mathrm{L}$ of DNA extract in $25 \mu \mathrm{L}$ reactions. Thermocycling was done as follows: initial denaturation at $95^{\circ} \mathrm{C}$ for 1 minute, 30 cycles of denaturation $\left(95^{\circ} \mathrm{C} 30 \mathrm{~s}\right)$ - annealing (16S: $50^{\circ} \mathrm{C} /$ ITS: $52^{\circ} \mathrm{C}$ for $\left.30 \mathrm{~s}\right)$ - elongation $\left(72^{\circ} \mathrm{C} 1 \mathrm{~min}\right)$, and a final, 5 min extension at $72^{\circ} \mathrm{C}$. Blanks were included to ensure absence of DNA amplification when no soil was added in DNA extraction kits. Positive amplicons were purified and sequenced using the Illumina MiSeq technology (Genome Québec Innovation Center).

Sequences were demultiplexed and paired-ends were merged in QIIME (Caporaso et al. , 2010), after which we proceeded to a quality filtering (quality score $>25$ ) and a removal of sequences with homopolymers longer than 10 bases. Chimera removal and operational taxonomical unit (OTU) clustering was performed in the open source software VSEARCH (Rognes et al. , 2016), at a 97\% similarity threshold. Taxonomy was assigned in QIIME using the curated databases Silva and UNITE (Pruesse et al. , 2007; Abarenkov et al. , 2010). We removed OTUs occurring in only one sample and occurrences with 5 reads or less, considering these as potential artefacts. We rarefied our OTU tables (16S and ITS) to 8000 reads per sample for fungi and 1100 reads for prokaryotes to correct for imbalanced sequencing depth per sample, due to the stochastic nature of sequencing. Sequence data were deposited in SRA under project \# 7716646.

\section{Statistical analyses}

What microbial guilds cause PSF? 
To identify microbial OTUs specifically associated with positive or negative PSF for Bromus and/or Koeleria , we conducted an indicator species analysis (Dufrêne \& Legendre, 1997). To this end, we first created bins of soil inocula that were associated with altered biomass relative to uninoculated plants for either of our plant species, or both. We had 9 bins, with a factorial combination of plants to be influenced ( 2 species: Bromus or Koeleria ) and 3 types of impact on plant growth (positive, negative or neutral) $\left(3^{2}=9\right.$ combinations). To get a plant growth threshold from which plant performance would be considered increased or decreased, we computed plant growth responses to all inocula as $t$-scores:

$$
t=\frac{G_{\mathrm{in}}-G_{\mathrm{st}}}{\left(\frac{\mathrm{SD}_{\mathrm{in}}}{\sqrt{n}}\right)}
$$

, where $G_{i n}$ represents mean growth with the inoculum, $G_{s t}$ is the mean growth in sterile soil only, and $S D_{i n}$ and $n$ are, respectively, the standard deviation in growth of inoculated pots, and the number of inoculated pots. We thus considered the soil inoculum to have a positive impact on plant growth (i.e. a positive plant-soil feedback) if growth was higher in inoculated soil relative to uninoculated soil, and vice versa for negative PSF. We identified a threshold $t$-score corresponding to an $80 \%$ confidence interval with our corresponding number of degrees of freedom $(d . f .=13)$. In other words, we considered the PSF significantly different from 0 if there was less than a $20 \%$ probability that such a growth difference inoculated and control plants had arisen by chance. As this $20 \%$ threshold was selected arbitrarily, we conducted a sensitivity analysis and show that the number of indicator OTUs retrieved is fairly robust to the threshold chosen (Fig. S2). The indicator species analyses were conducted using the $\mathrm{R}$ package indicspecies (De Caceres \& Legendre, 2009). Despite the high number of individual tests in these analyses, we kept the $a$ threshold at 0.05 . $P$-value correction methods would have yielded way too stringent thresholds to consider associations as significant, given the very high number of rare microbial OTUs. We thus validated the robustness of our indicator species analysis to type I errors by running 1000 indicator species analyses on randomized datasets (microbial metacommunities shuffled by keeping number of sequence reads constant by soil sample and by microbial OTU), and found that on average, by chance, we retrieve $~ 40$ and 80 indicator prokaryotes and fungi respectively (Fig. S3). However, we also compared the identity of the indicator OTUs retrieved by multiple indicator species analyses on our real dataset vs. on our randomized datasets, and found that indicator OTUs were very constant from run to run in the former, but much more variable in the latter (Fig. S4). This shows that the indicator OTUs reported here are not likely to be random subsets of our metacommunity that have arisen as type I errors.

In order to determine the contribution of different microbial guilds to PSF, we assigned indicator microbial OTUs to guilds based on the literature. For prokaryotes, we relied on published papers, manually querying scientific search engines for papers mentioning these taxa. Prokaryotic OTUs that could not be assigned to a tentative guild (21 out of 66 indicator OTUs) were left out of downstream analyses. To assign fungal OTUs to guilds, we used the open-source database FunGuild (Nguyenet al. , 2016). After guild assignment, we conducted $\chi^{2}$-tests to determine if certain microbial guilds were disproportionately associated with certain PSF types (e.g., pathogens overrepresented as indicator OTUs of negative PSF). We note here that with indicator species analysis, we were unlikely to assign generalist/ubiquitous taxa to any of our specific PSF "bins", because the analysis is by essence based on variations in relative abundances. Thus, if some pathogens, for example, are very widespread in the microbial metacommunity, they are unlikely to be retrieved as indicator of negative PSF. To address this issue, we systematically assigned all fungal OTUs to a guild using FunGuild, and we assigned the most widespread prokaryotes OTUs to guilds manually. This way, we could validate that the absence of a given guild to particular PSF bins was not an artefact, due to the ubiquity of taxa from that guild.

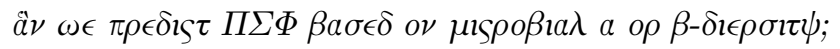

We used linear mixed models (LMMs) to regress measured PSF against prokaryotic and fungal (1) richness and (2) Shannon's diversity (exponential form; Hill, 1973), as estimators of $a$-diversity. We also included 
prokaryotic and fungal community structure as predictors using site loadings from a non-metric multidimensional scaling (using Hellinger-transformed microbial community data) constrained over two axes. We constructed separate models to predict Koeleria vsBromus growth responses, including the identity of the block from which the inoculum came from as a random factor in the models, and the state variable indicating whether the sample came, within the block, from the Bromus -invaded plot vs the native vegetation plot. We used the R package nlme (Pinheiro et al. , 2020) for LMMs construction.

Do microorganisms causing PSF respond more strongly to plants or soil?

We used redundancy analyses to regress microbial community structure against environmental data matrices. Environmental matrices combined (1) soil properties (Mehlich-III extractible $\mathrm{P}, \mathrm{NH}_{4}{ }^{+}, \mathrm{NO}_{3}{ }^{-}, \mathrm{pH}$ and gravimetric moisture measured in fresh soils, as described in Chagnon et al. , 2018) and (2) plant community structure. To include the latter as a predictor of microbial community structure, we used the first 5 axes of a principal component analysis (using Hellinger-transformed plant abundance data), which collectively explained $75 \%$ of the variance in plant community structure (Table S1). This yielded RDAs with 10 explanatory variables ( 5 soil and 5 plant predictors, respectively). We ran RDAs separately for prokaryotes and fungi. For each, we conducted one RDA with the indicator OTUs, and one with the rest of the microbiome (i.e., the non-indicator OTUs). Then, to verify whether the indicator OTUs responded idiosyncratically to the explanatory variables (hypothesizing that they would be tied more strongly to plant community structure), we evaluated the co-inertia between the axes loadings of the explanatory variables using Procrustes rotations using the $\mathrm{R}$ packagevegan (Oksanen et al. , 2019). A poor correlation between these axes loadings would indicate those explanatory variables that best describe the indicator OTUs are not the same as for the rest of the microbiome.

\section{Results}

Each soil inoculum contained 125 prokaryotic and 150 fungal OTUs (Fig. S5), for a regional total of 887 and 1534 OTUs, respectively. These inocula tended to generate neutral to negative growth responses for Koeleria, but positive responses for Bromus, with a lack of correlation between the PSF experienced by the two species (Fig. 1, Spearman's $\rho=0.042, P=0.53$ ). Bromus and Koeleria were also influenced by different OTUs as evidenced by our indicator species analysis (Fig. 2). However, no microbial OTU was found to influence Koeleriaonly. This could indicate a lower sensitivity of Koeleria to the soil microbiome, which is in line with its plant growth responses ( $t$-score values) spanning less units than for Bromus (Koeleria $[-3,1]$ except for an outlier at +3 ; Bromus [-4,4]) (Fig. 1). We note a complete absence of OTUs influencing positively one species but negatively the other. Such combinations of ecological outcomes are the ones expected to drive the strongest PSF, yet are absent from a metacommunity of over 2400 microbial OTUs.

\section{What microbial guilds are causing PSF?}

We found 66 indicator prokaryotes out of 887 OTUs and 110 indicator fungi out of 1534 OTUs. Guild affiliation was possible for 45 prokaryotes and 33 fungi among our indicator OTUs. We found no significant overrepresentation of fungal pathogens as indicator OTUs of negative plant growth response (Fig. $2, \chi^{2}=$ 9.79 , d.f. $=10, P=0.46$, Fig. 2). Rather, only one of the 33 indicator fungi was a pathogen (negatively affectingBromus ). All the remaining 32 indicator fungi were saprotrophs, and either positively (9) or negatively (3) affected both plants, or negatively affected Bromus only (20). Twelve of the 33 indicator fungi (36\%) similarly affected Bromus and Koeleria, while the remainder (64\%) had species-specific effects (a necessary condition for microorganisms to drive species-specific PSF). Regarding the prokaryotes, of the 66 indicator OTUs, the majority (37) were associated with improved performance for both Bromus and Koeleria . Conversely, 6 negatively affected Bromus growth and 23 were detrimental to both species. Thus, as opposed to fungi, few indicator prokaryotes $(9 \%, 6$ out of 66$)$ had species-specific effects on plants. Indicator prokaryotes were mostly related to $\mathrm{N}$ cycling (bacterial and archaeal nitrifiers) or were primary producers (Chloroflexi spp. ). Interestingly, while the vast majority of prokaryotic saprotrophs were associated with positive plant growth responses (18 out of 26 saprotrophic OTUs), fungal saprotrophs tended to be associated with a negative rather than positive plant growth response (23 vs. 9 OTUs, respectively). This contrast 
between prokaryotes and fungi was statistically significant $\left(\chi^{2}=8.16\right.$, d.f. $\left.=1, P=0.004\right)$.

There was a surprising scarcity of symbiotic indicator OTUs. Out of the 18 arbuscular mycorrhizal fungi and the 16 fungal endophytes (mostly dark septate endophytes) found in our dataset, none were identified as indicator OTU. Similarly, among prokaryotes, we did not find any of the typical plant-growth promoting lineages (e.g., Pseudomonas spp .,Burkholderia spp ., Bacillus spp .) to be associated with consistently improved plant growth in our greenhouse assay, even though they were present in the total microbiome.

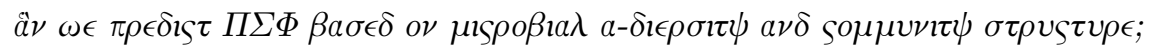

PSFs were poorly predicted by microbial $\alpha$-diversity, considering both Shannon's diversity or OTU richness (Table 1). Koeleria was not responsive either to microbial community structure (i.e., ordination axes scores), while Bromus growth was significantly influenced by fungal community structure $(P=0.03$, Table 1$)$. Bromusgrew better with inocula from Bromus -invaded plots (i.e., positive PSF), while the reverse was true for Koeleria (Table 1). Collectively, these contrasts between our two plant species provide further evidence for the species-specific nature of plant response to microbial community structure.

Do PSF-causing microorganisms respond more to vegetation than to soil?

Indicator OTUs causing PSF were not more strongly associated with plant community structure than with soil properties, as compared to the rest of the soil microbiome (Fig. 3). In fact, procrustean analyses revealed a very strong correlation between the predictors of microbial community structure when comparing indicator vs non-indicator prokaryotes $(r=0.86, P=0.002)$. A similar result was found for fungi $(r=$ 0.88, $P<0.001)$. For both prokaryotic and fungal communities, the strongest predictors were soil $\mathrm{pH}$, moisture and $\mathrm{N}$ levels, as well as two plant community structure ordination axes associated mainly with the abundances of Bromusinermis , Nassella viridula and Carex stenophylla(plant ordination axes 2 and 3, jointly explaining $34 \%$ of plant community structure, Fig. 3, Table S1). Although we had found that high-pH, high-moisture and low-fertility soils were conducive to negative PSF in these soils (Chagnon et al. , 2018), we did not find strong associations between these soil properties and pathogenic indicator OTUs in our canonical ordinations (Fig. S6). Likewise, we did not find that the proportion of fungal sequence reads belonging to pathogenic OTUs was significantly influenced by soil properties (assessed through generalized additive mixed models), except for a very weak unimodal trend with soil moisture (Fig. S7). However, this trend explained less than $5 \%$ of the variance. Collectively, these results further confirm that pathogens were not strongly associated with the decrease in plant growth observed with inocula collected from low-nutrients, high-pH and high-moisture soils (Chagnon et al. , 2018).

\section{Discussion}

Overall, our results support the idea that soil microorganisms are drivers of PSF: they influence plant growth in a species-specific way (Fig. 1,2) and they respond, to some extent, to plant community structure (Fig. 3 ). However, we show that contrary to expectations, the main microbial drivers of PSF were not pathogens. We also show that contrary to other studies arguing that microbial $\alpha$-diversity is a major driver of various ecosystem functions and plant performance (e.g., Delgado-Baquerizo et al. , 2016; Wagg et al. , 2014), here plant growth response was much more tied to the presence of specific microorganisms (Fig. 2), rather than to community-level properties such as richness or diversity (Table 1).

The role for non-pathogenic microorganisms in PSF

Many microbial OTUs were indicators of negative PSF in our system (Fig. 2), which is consistent with many other studies showing accumulation of soilborne detrimental organisms by plants (e.g., Mangan et al. , 2010; Bagchi et al. , 2014; Laliberté et al. , 2015). However, our results also suggest that nonpathogenic soil microorganisms are an overlooked group of soil biota that may drive negative PSF and plant coexistence. Soil microorganisms are known to be efficient competitors for mineral nutrients, especially $\mathrm{N}$ (Liu et al. , 2016). They have high nutrient uptake capacity and high demand for it (Kuzyakov \& Xu, 2013). Denitrifying prokaryotes efficiently compete against roots for $\mathrm{NO}_{3}{ }^{-}$when roots deplete soil $\mathrm{O}_{2}$ through respiration (Philippot et al. , 2002, 2009). Nitrifiers, on the other hand, compete with roots for $\mathrm{NH}_{4}^{+}$, 
which they require as an energy source (Prosser, 1990). Knowing that N mineralization rates in unfertilized grasslands are expected to be insufficient to meet both microbial and plant demand (Woodmansee et al. , 1981), exploitation competition between plant and soil microorganisms is expected to be intense in our Npoor natural grassland. As a result, a plant that accumulates microbial competitors for $\mathrm{N}$ in its rhizosphere may suffer from negative PSF.

Our evidence that non-pathogenic microbes can cause negative PSF should also lead to reconsideration of the intended target of a variety of root exudates. For example, antimicrobial compounds secreted by plants (e.g., quinones, terpenoids, flavonoids) (Brigham et al. , 1999; Bais, 2006) may target soil microorganisms broadly. Not strictly soilborne pathogens. Bromus, for example, has specifically been found to produce surprisingly high amounts of polyphenol oxidase in its rhizosphere (Holzapfel et al. , 2010), a class of enzymes known to degrade mycotoxins (e.g., Alberts et al. , 2009). Plants are also known to interfere broadly with soil microbial growth by exuding protons, phenolics, glucanases or chitinase (Weisskoppf et al., 2006). Conversely, many non-pathogenic microorganisms have been demonstrated to inhibit plant nutrient uptake through inhibition of mycorrhiza formation (Duponnois \& Garbaye, 1991), or degradation of nutrient-mobilizing compounds secreted by plants (e.g., organic acids) (Marschner et al., 2011). Taken collectively, all these mechanisms bring compelling evidence to the idea that plants are involved in antagonistic interactions with soil microorganisms broadly, not only the ones that are trying to colonize their tissues (i.e., pathogens).

Positive PSF were also common in our system, especially forBromus (Fig. 1). These were not linked to mutualistic/symbiotic OTUs (Fig. 2), even though these guilds were well represented in our microbial metacommunity (which included Bacillus spp.,Pseudomonas spp., arbuscular mycorrhizal fungi, dark septate endophytes, etc.). This could be explained by the fact that the impact of belowground symbionts on plants tend oscillate along a mutualism-parasitism continuum, which is contingent upon the abiotic environment (Johnson et al. , 1997; Hirsch, 2004). More generally, this shows how positive PSF must be interpreted beyond the idea of mutualistic symbiont accumulation. Our indicator OTUs for positive PSF were non-symbiotic nutrient cyclers (fungal saprotrophs, prokaryotic nitrifiers, etc.), showing that plants can benefit from microorganisms contributing to nutrient cycling more broadly, and not necessarily in a symbiotic manner. We should also keep in mind that mutualistic guilds (e.g., arbuscular mycorrhizal fungi) can drive negative PSF (Bever, 1999, 2002; Chagnon et al. , unpublished data ).

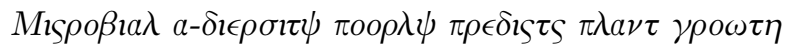

Even if microbial $\alpha$-diversity has been suggested to drive crucial ecosystem functions including plant productivity and diversity (van der Heijden et al. , 1998; Delgado-Baquerizo et al. , 2016; Laforest-Lapointe et al. , 2017), here we found that microbial richness and Shannon's diversity are poor predictors of PSF. Plants responded to specific OTUs (Fig. 2), or groups of microorganisms (Table 1), but not to community diversity per se. This, however, does not completely rule out microbial $\alpha$-diversity as a potentially important component of PSF. If there exists concurrent variation in (1) the impact of different plants on microbial diversity and (2) the response of these different plants to such diversity, then non-neutral PSF are to be expected. We found poor evidence for the latter in our study (Table 1).

\section{Are PSF-driving microorganisms strongly tied to vegetation structure?}

A major, and often taken for granted, assumption of PSF theory is that soil microorganisms will respond to shifts in plant community structure. This is a necessary prerequisite for plant and soil microbial communities to oscillate and eventually converge to a stable equilibrium (Bever, 1999). While many studies have found soil organisms to be responsive to plant community structure (e.g., Eom et al. , 2000; Bezemer et al. , 2010; Chagnon et al. , 2020), many others have found that soil is rather the dominant filter (e.g., Dumbrellet al. , 2010). Here, we found that plant community structure and soil properties jointly determined microbial community structure (Fig. 3). Interestingly, we found that PSF-causing OTUs were not more strongly tied to the plant community than to the soil. This suggests that if soil properties are sufficiently heterogeneous at local scales, it could reduce the importance of PSF as drivers of plant and microbial community assembly. In this context, the soil microbiome could be more tied to soil properties and less responsive to plant community 
structure, thereby disrupting the feedback dynamics between plants and soil microorganisms.

PSF and grassland invasion by Bromus

Bromus tended to experience positive growth responses to soil inocula, especially those from Bromus invaded plots (Table 1). This could appear as evidence for enemy release, whereby the invasiveBromus is escaping pathogens that drive negative PSF on native species (e.g., Klironomos, 2002). However, the lack of pathogenic OTUs specifically detrimental to Koeleria (Fig. 2) fails to support this hypothesis. Positive PSF developed by Bromus in these grasslands may rather arise from its capacity to establish beneficial interactions with non-symbiotic, nutrient-cycling microorganisms. This deserves further consideration in invasion ecology, with many study providing evidence for exotic species experiencing less negative PSF (Klironomos et al. , 2002; Reinhart et al. , 2003; Aldorfovaet al. , 2020), but few actually demonstrating the implications for soil-borne enemies in this pattern (e.g., Beckstead \& Parker, 2003). Exotic species could be more versatile in developing positive interactions with foreign soil microbiota. Our results show (Fig. 2) that non-pathogenic and non-symbiotic microorganisms deserve more attention that they have received in prior research on PSF in the context of plant invasion (e.g., Vogelsang \& Bever, 2009; Zhang et al., 2010).

\section{Conclusion}

Literature on PSFs is in need for more mechanistic approaches to unravel the biological drivers of the observed plant growth responses to soil biota. In this study, we provide compelling evidence contradicting the common assumption that negative plant growth response to soil biota is driven by pathogenic microorganisms. We also show that positive plant growth responses are very rarely driven by well-known nutritional or biocontrol microorganisms such as plant growth promoting bacteria or mycorrhizal fungi. Rather, our results point to chemoautotrophs (N-cyclers) and saprotrophs as the main drivers of plant growth response in our system. This, as a whole, constitutes a plea to bring back nutrient cycling as a central component for the development of PSF (e.g., in't Zandt et al. , in press ), in a literature that has become dominated by trophic, top-down interactions (i.e., pathogens and nutritional symbionts).

\section{Acknowledgements}

The authors acknowledge the technical support of Gisela Stotz, Alec Carrigy, Logan Fairgrieve-Park, Megan Ljubotina and Valerie Marshall in the field. P.-L.C. was funded by the Killam Trust and the Fonds de Recherche Québécois Nature et Technologies (FRQNT). J.F.C. received support from the Natural Sciences and Engineering Research Council (NSERC) and the Rangeland Research Institute (research grant).

\section{Figure Legends}

Figure 1. Spearman's rank correlation between the growth response of Bromus and Koeleria to our soil inocula. Responses are presented as $t$-scores (unitless) based on the comparison of plant growth for inoculated replicates vs. for sterile controls.

Figure 2. Microbial guilds associated with plant growth response to our soil inocula. In a) for prokaryotes, and in b) for fungi, we show the number of OTUs that are beneficial (green "+" symbols) or detrimental (red "- " symbols) to Bromus and/or Koeleria . "0" in the left panels indicate no plant growth response. Only bins $($ e.g.,++ ) that had associated OTUs were included though all were tested.

Figure 3. Redundancy analyses (RDAs) depicting the association between OTUs and their predictors (i.e., soil properties and plant community structure). a) and b) show RDAs for the non-indicator prokaryotes and the indicator prokaryotes, respectively. Likewise, c) and d) show RDAs for the non-indicator fungi the indicator fungi, respectively. Each symbol represents a single OTU, and is colour coded in b) and d) as a function of its impact on Bromus and/orKoeleria . Percentages on the canonical axes indicate the amount of inertia constrained. Abbreviations: $\mathrm{NH}_{4}{ }^{+}$and $\mathrm{NO}_{3}{ }^{-}$are respectively, soil KCl-extractible ammonium and nitrates; $\mathrm{PO}_{4}{ }^{3-}=$ Mehlich-III-extractible phosphorus ; \% Moist = gravimetric soil moisture ; Veg 1 to $5=$ site scores from the 5 principal components of the plant community ordination (PCA on Hellinger-transformed community data). 


\section{References}

Abarenkov, K., Henrik Nilsson, R., Larsson, K.-H., Alexander, I.J., Eberhardt, U., Erland, S., et al. (2010). The UNITE database for molecular identification of fungi - recent updates and future perspectives. New Phytol. , 186, 281-285.

Agrios, G. (2005). Plant Pathology, $5^{\text {th }}$ ed. Academic Press, New York, USA.

Alberts, J.F., Gelderblom, W.C.A., Botha, A. \& van Zyl, W.H. (2009). Degradation of aflatoxin B1 by fungal laccase enzymes. Int. J. Food Microbiol., 135, 47-52.

Albornoz, F.E., Burgess, T.I., Lambers, H., Etchells, H. \& Laliberté, E. (2017). Native soilborne pathogens equalize differences in competitive ability between plants of contrasting nutrient-acquisition strategies. $J$. Ecol. , 105, 549-557.

Aldorfová, A., Knobová, P. \& Münzbergová, Z. (2020). Plant-soil feedback contributes to predicting plant invasiveness of 68 alien plant species differing in invasive status. Oikos , 129, 1257-1270.

Bagchi, R., Gallery, R.E., Gripenberg, S., Gurr, S.J., Narayan, L., Addis, C.E., et al. (2014). Pathogens and insect herbivores drive rainforest plant diversity and composition. Nature , 506, 85-88.

Bagchi, R., Press, M.C. \& Scholes, J.D. (2010). Evolutionary history and distance dependence control survival of dipterocarp seedlings.Ecol. Lett. , 13, 51-59.

Bais, H.P., Weir, T.L., Perry, L.G., Gilroy, S. \& Vivanco, J.M. (2006). The role of root exudates in rhizosphere interactions with plants and other organisms. Annu. Rev. Plant Biol. , 57, 233-266.

Bauer, J.T., Mack, K.M.L. \& Bever, J.D. (2015). Plant-soil feedbacks as drivers of succession: evidence from remnant and restored tallgrass prairies. Ecosphere, 6, art158.

Beckstead, J. \& Parker, I.M. (2003). Invasiveness of Ammophila arenaria : release from soil-borne pathogens? Ecology , 84, 2824-2831.

Bennett, J.A. \& Klironomos, J. (2018). Climate, but not trait, effects on plant-soil feedback depend on mycorrhizal type in temperate forests.Ecosphere, 9, e02132.

Berendse, F. (1994). Litter decomposability - a neglected component of plant fitness. J. Ecol., 82, 187.

Bever, J.D. (1999). Dynamics within mutualism and the maintenance of diversity: inference from a model of interguild frequency dependence.Ecol. Lett. , 2, 52-61.

Bever, J.D. (2002). Negative feedback within a mutualism: host-specific growth of mycorrhizal fungi reduces plant benefit. Proc. R. Soc. London. Ser. B Biol. Sci. , 269, 2595-2601.

Bever, J.D., Dickie, I.A., Facelli, E., Facelli, J.M., Klironomos, J., Moora, M., et al. (2010). Rooting theories of plant community ecology in microbial interactions. Trends Ecol. Evol.

Bever, J.D., Mangan, S.A. \& Alexander, H.M. (2015). Maintenance of plant species diversity by pathogens. Annu. Rev. Ecol. Evol. Syst., 46, 305-325.

Bever, J.D., Westover, K.M. \& Antonovics, J. (1997). Incorporating the soil community into plant population dynamics: the utility of the feedback approach. J. Ecol. , 85, 561.

Bezemer, T.M., Fountain, M.T., Barea, J.M., Christensen, S., Dekker, S.C., Duyts, H., et al. (2010). Divergent composition but similar function of soil food webs of individual plants: plant species and community effects. Ecology , 91, 3027-3036.

Brigham, L.A., Michaels, P.J. \& Flores, H.E. (1999). Cell-specific production and antimicrobial activity of naphthoquinones in roots of Lithospermum erythrorhizon . Plant Physiol. , 119, 417-428. 
Bryant, J.P., Provenza, F.D., Pastor, J., Reichardt, P.B., Clausen, T.P. \& du Toit, J.T. (1991). Interactions between woody plants and browsing mammals mediated by secondary metabolites. Annu. Rev. Ecol. Syst., $22,431-446$.

Cáceres, M. De \& Legendre, P. (2009). Associations between species and groups of sites: indices and statistical inference. Ecology, 90, 3566-3574.

Caporaso, J.G., Kuczynski, J., Stombaugh, J., Bittinger, K., Bushman, F.D., Costello, E.K., et al. (2010). QIIME allows analysis of high-throughput community sequencing data. Nat. Methods , 7, 335-336.

Chagnon, P., Bradley, R.L. \& Klironomos, J.N. (2020). Mycorrhizal network assembly in a community context: The presence of neighbours matters. J. Ecol. , 108, 366-377.

Chagnon, P.-L., Brown, C., Stotz, G.C. \& Cahill, J.F. (2018). Soil biotic quality lacks spatial structure and is positively associated with fertility in a northern grassland. J. Ecol. , 106, 195-206.

Chapin, F.S. (1980). The mineral nutrition of wild plants. Annu. Rev. Ecol. Syst. , 11, 233-260.

Chapin, F.S. (1991). Integrated responses of plants to stress.Bioscience , 41, 29-36.

Chapin, F.S., Vitousek, P.M. \& Van Cleve, K. (1986). The nature of nutrient limitation in plant communities. Am. Nat. , 127, 48-58.

Cortois, R., Schröder-Georgi, T., Weigelt, A., Putten, W.H. \& De Deyn, G.B. (2016). Plant-soil feedbacks: role of plant functional group and plant traits. J. Ecol. , 104, 1608-1617.

de Kroon, H., Hendriks, M., van Ruijven, J., Ravenek, J., Padilla, F.M., Jongejans, E., et al. (2012). Root responses to nutrients and soil biota: drivers of species coexistence and ecosystem productivity.J. Ecol. , $100,6-15$.

Delgado-Baquerizo, M., Maestre, F.T., Reich, P.B., Jeffries, T.C., Gaitan, J.J., Encinar, D., et al. (2016). Microbial diversity drives multifunctionality in terrestrial ecosystems. Nat. Commun., 7, 10541.

Dobson, A. \& Crawley, M. (1994). Pathogens and the structure of plant communities. Trends Ecol. Evol. , 9, 393-398.

Dominguez-Begines, J., Avila, J.M., Garcia, L. V. \& Gomez-Aparicio, L. (2020). Soil-borne pathogens as determinants of regeneration patterns at community level in Mediterranean forests. New Phytol. , 227, $588-600$.

Dufrene, M. \& Legendre, P. (1997). Species assemblages and indicator species: the need for a flexible asymmetrical approach. Ecol. Monogr. , 67, 345.

Dumbrell, A.J., Nelson, M., Helgason, T., Dytham, C. \& Fitter, A.H. (2010). Relative roles of niche and neutral processes in structuring a soil microbial community. ISME J. , 4, 337-345.

Duponnois, R. \& Garbaye, J. (1991). Mycorrhization helper bacteria associated with the Douglas fir-Laccaria laccata symbiosis: effects in aseptic and in glasshouse conditions. Ann. des Sci. For. , 48, 239-251.

Eom, A.H., Hartnett, D.C. \& Wilson, G.W.T. (2000). Host plant species effects on arbuscular mycorrhizal fungal communities in tallgrass prairie. Oecologia , 122, 435-444.

Fireman, M. \& Hayward, H.E. (1952). Indicator significance of some shrubs in the escalante desert, Utah. Bot. Gaz. , 114, 143-155.

Fraser, L.H., Pither, J., Jentsch, A., Sternberg, M., Zobel, M., Askarizadeh, D., et al. (2015). Worldwide evidence of a unimodal relationship between productivity and plant species richness.Science , 349, 302-305.

Gardes, M. \& Bruns, T.D. (1993). ITS primers with enhanced specificity for basidiomycetes - application to the identification of mycorrhizae and rusts. Mol. Ecol. , 2, 113-118. 
Gilbert, J.A., Jansson, J.K. \& Knight, R. (2014). The Earth Microbiome project: successes and aspirations. BMC Biol. , 12, 69.

Hector, A., Hautier, Y., Saner, P., Wacker, L., Bagchi, R., Joshi, J., et al. (2010). General stabilizing effects of plant diversity on grassland productivity through population asynchrony and overyielding.Ecology , 91, $2213-2220$.

Hill, M.O. (1973). Diversity and evenness: a unifying notation and its consequences. Ecology , 54, 427-432.

Hirsch, A. M. (2004). Plant-microbe symbioses: a continuum from commensalism to parasitism. Symbiosis $, 37,345-363$.

Hobbie, S.E. (1992). Effects of plant species on nutrient cycling. Trends Ecol. Evol. , 7, 336-339.

Hobbie, S.E. (2015). Plant species effects on nutrient cycling: revisiting litter feedbacks. Trends Ecol. Evol. , 30, 357-363.

Hodge, A., Robinson, D. \& Fitter, A. (2000). Are microorganisms more effective than plants at competing for nitrogen? Trends Plant Sci. , 5, 304-308.

Holzapfel, C., Shahrokh, P. \& Kafkewitz, D. (2010). Polyphenol oxidase activity in the roots of seedlings of Bromus (Poaceae) and other grass genera. Am. J. Bot. , 97, 1195-1199.

Horner, J.D., Gosz, J.R. \& Cates, R.G. (1988). The role of carbon-based plant secondary metabolites in decomposition in terrestrial ecosystems.Am. Nat. , 132, 869-883.

in 't Zandt, D., Hoekstra, N.J., Wagemaker, C.A.M., Caluwe, H., Smit-Tiekstra, A.E., Visser, E.J.W., et al. . Local soil legacy effects in a multispecies grassland community are underlain by root foraging and soil nutrient availability. J. Ecol. , in press. doi : 10.1111/1365-2745.13449

Johnson, N.C., Graham, J.H. \& Smith, F.A. (1997). Functioning of mycorrhizal associations along the mutualism-parasitism continuum. New Phytol. , 135, 575-585.

Klironomos, J.N. (2002). Feedback with soil biota contributes to plant rarity and invasiveness in communities. Nature , 417, 67-70.

Kuiters, A.T. (1990). Role of phenolic substances from decomposing forest litter in plant- soil interactions. Acta Bot. Neerl.

Kulmatiski, A., Beard, K.H., Stevens, J.R. \& Cobbold, S.M. (2008). Plant-soil feedbacks: a meta-analytical review. Ecol. Lett. , 11, 980-992.

Kuzyakov, Y. \& Xu, X. (2013). Competition between roots and microorganisms for nitrogen: mechanisms and ecological relevance. New Phytol. , 198, 656-669.

Laforest-Lapointe, I., Paquette, A., Messier, C. \& Kembel, S.W. (2017). Leaf bacterial diversity mediates plant diversity and ecosystem function relationships. Nature, 546, 145-147.

Laliberte, E., Lambers, H., Burgess, T.I. \& Wright, S.J. (2015). Phosphorus limitation, soil-borne pathogens and the coexistence of plant species in hyperdiverse forests and shrublands. New Phytol. , 206, 507-521.

Liu, Q., Qiao, N., Xu, X., Xin, X., Han, J.Y., Tian, Y., et al.(2016). Nitrogen acquisition by plants and microorganisms in a temperate grassland. Sci. Rep. , 6, 22642.

Mangan, S.A., Schnitzer, S.A., Herre, E.A., Mack, K.M.L., Valencia, M.C., Sanchez, E.I., et al. (2010). Negative plant-soil feedback predicts tree-species relative abundance in a tropical forest.Nature , 466, 752 755.

Marschner, P., Crowley, D. \& Rengel, Z. (2011). Rhizosphere interactions between microorganisms and plants govern iron and phosphorus acquisition along the root axis - model and research methods. Soil Biol. Biochem. , 43, 883-894. 
Mills, K.E. \& Bever, J.D. (1998). Maintenance of diversity within plant communities: Soil pathogens as agents of negative feedback.Ecology , 79, 1595-1601.

Nguyen, N.H., Song, Z., Bates, S.T., Branco, S., Tedersoo, L., Menke, J., et al. (2016). FUNGuild: An open annotation tool for parsing fungal community datasets by ecological guild. Fungal Ecol. , 20, 241-248.

Oksanen, J., Blanchet, F.G., Friendly, M., Kindt, R., Legendre, P., McGlinn, D., et al. (2019). vegan: community ecology package. $\mathrm{R}$ package version $2.5-2$. Cran $R$.

Olff, H., Hoorens, B., de Goede, R.G.M., van der Putten, W.H. \& Gleichman, J.M. (2000). Small-scale shifting mosaics of two dominant grassland species: the possible role of soil-borne pathogens.Oecologia , 125, $45-54$.

Packer, A. \& Clay, K. (2000). Soil pathogens and spatial patterns of seedling mortality in a temperate tree. Nature , 404, 278-281.

Brinkman, P.E., Van der Putten, W.H., Bakker, E.-J. \& Verhoeven, K.J.F. (2010). Plant-soil feedback: experimental approaches, statistical analyses and ecological interpretations. J. Ecol. , 98, 1063-1073.

Philippot, L., Hallin, S., Borjesson, G. \& Baggs, E.M. (2009). Biochemical cycling in the rhizosphere having an impact on global change. Plant Soil , 321, 61-81.

Philippot, L., Piutti, S., Martin-Laurent, F., Hallet, S. \& Germon, J.C. (2002). Molecular analysis of the nitrate-reducing community from unplanted and maize-planted soils. Appl. Environ. Microbiol. , 68, 6121-6128.

Pinheiro, J., Bates, D., DebRoy, S., \& Sarkar, D., R Core Team (2020). nlme: linear and nonlinear mixed effects models. R package version 3.1-148

Prosser, J.I. (1990). Autotrophic nitrification in bacteria. In:Advances in microbial physiology (Eds Rose, A.H., \& Tempest, D.W.). pp. 125-181.

Pruesse, E., Quast, C., Knittel, K., Fuchs, B.M., Ludwig, W., Peplies, J., et al. (2007). SILVA: a comprehensive online resource for quality checked and aligned ribosomal RNA sequence data compatible with ARB. Nucleic Acids Res. , 35, 7188-7196.

Reinhart, K.O., Packer, A., Van der Putten, W.H. \& Clay, K. (2003). Plant-soil biota interactions and spatial distribution of black cherry in its native and invasive ranges. Ecol. Lett. , 6, 1046-1050.

Reinhart, K.O. (2012). The organization of plant communities: negative plant-soil feedbacks and semiarid grasslands. Ecology , 93, 2377-2385.

Revillini, D., Gehring, C.A. \& Johnson, N.C. (2016). The role of locally adapted mycorrhizas and rhizobacteria in plant-soil feedback systems. Funct. Ecol. , 30, 1086-1098.

Rognes, T., Flouri, T., Nichols, B., Quince, C. \& Mahe, F. (2016). VSEARCH: a versatile open source tool for metagenomics. PeerJ , 4, e2584.

Sarmiento, C., Zalamea, P.-C., Dalling, J.W., Davis, A.S., Stump, S.M., U'Ren, J.M., et al. (2017). Soilborne fungi have host affinity and host-specific effects on seed germination and survival in a lowland tropical forest. Proc. Natl. Acad. Sci. , 114, 11458-11463.

Schnitzer, S.A., Klironomos, J.N., HilleRisLambers, J., Kinkel, L.L., Reich, P.B., Xiao, K., et al. (2011). Soil microbes drive the classic plant diversity-productivity pattern. Ecology , 92, 296-303.

Shorthouse, J. (2010). Ecoregions of Canada's prairie grasslands. In J. Shorthouse \& K. D. Floate (Eds.), Arthropods of Canadian grasslands: Ecology and interactions in grassland habitats (pp. 53-81). Ottawa, Canada: Biological Survey of Canada. 
Smith-Ramesh, L.M. \& Reynolds, H.L. (2017). The next frontier of plant-soil feedback research: unraveling context dependence across biotic and abiotic gradients. J. Veg. Sci. , 28, 484-494.

Tardif, A. \& Shipley, B. (2015). The relationship between functional dispersion of mixed-species leaf litter mixtures and species' interactions during decomposition. Oikos , 124, 1050-1057.

Thrall, P.H., Bever, J.D., Mihail, J.D. \& Alexander, H.M. (1997). The population dynamics of annual plants and soil-borne fungal pathogens.J. Ecol. , 85, 313.

Thrall, P.H., Hochberg, M.E., Burdon, J.J. \& Bever, J.D. (2007). Coevolution of symbiotic mutualists and parasites in a community context. Trends Ecol. Evol. , 22, 120-126.

Tilman, D. (1980). Resources: a graphical-mechanistic approach to competition and predation. Am. Nat. , 116, 362-393.

van der Heijden, M.G.A., Klironomos, J.N., Ursic, M., Moutoglis, P., Streitwolf-Engel, R., Boller, T., et al. (1998). Mycorrhizal fungal diversity determines plant biodiversity, ecosystem variability and productivity. Nature , 396, 69-72.

van der Putten, W.H., Bardgett, R.D., Bever, J.D., Bezemer, T.M., Casper, B.B., Fukami, T., et al. (2013). Plant-soil feedbacks: the past, the present and future challenges. J. Ecol. , 101, 265-276.

Van der Putten, W.H., Van Dijk, C. \& Peters, B.A.M. (1993). Plant-specific soil-borne diseases contribute to succession in foredune vegetation. Nature, 362, 53-56.

van Ruijven, J., Ampt, E., Francioli, D. \& Mommer, L. (2020). Do soil-borne fungal pathogens mediate plant diversity-productivity relationships? Evidence and future opportunities. J. Ecol. , 108, 1810-1821.

Vogelsang, K.M. \& Bever, J.D. (2009). Mycorrhizal densities decline in association with nonnative plants and contribute to plant invasion.Ecology , 90, 399-407.

Wagg, C., Bender, S.F., Widmer, F. \& van der Heijden, M.G.A. (2014). Soil biodiversity and soil community composition determine ecosystem multifunctionality. Proc. Natl. Acad. Sci. , 111, 5266-5270.

Wang, X., Wang, Z., Jiang, P., He, Y., Mu, Y., Lv, X., et al.(2018). Bacterial diversity and community structure in the rhizosphere of four Ferula species. Sci. Rep. , 8, 5345.

Wedin, D.A. \& Tilman, D. (1990). Species effects on nitrogen cycling: a test with perennial grasses. Oecologia , 84, 433-441.

Weisskopf, L., Abou-mansour, E., Fromin, N., Tomasi, N., Santelia, D., Edelkott, I., et al. (2006). White lupin has developed a complex strategy to limit microbial degradation of secreted citrate required for phosphate acquisition. Plant, Cell Environ. , 29, 919-927.

White, T.J., Bruns, T., Lee, S. \& Taylor, J. (1990). Amplification and direct sequencing of fungal ribosomal RNA genes for phylogenetics. In: PCR Protocols. Elsevier, pp. 315-322.

Woodmansee, R. G., I. Vallis, \& J. J. Mott . (1981). Grassland nitrogen. Ecological Bulletin, 33: 443- 462.

Yang, C., Hamel, C., Gan, Y. \& Vujanovic, V. (2013). Pyrosequencing reveals how pulses influence rhizobacterial communities with feedback on wheat growth in the semiarid Prairie. Plant Soil , 367, 493-505.

Zhang, Q., Yang, R., Tang, J., Yang, H., Hu, S. \& Chen, X. (2010). Positive feedback between mycorrhizal fungi and plants influences plant invasion success and resistance to invasion. PLoS One, 5, e12380.

Zinke, P.J. (1962). The pattern of influence of individual forest trees on soil properties. Ecology , 43, $130-133$.

\section{Hosted file}


Table 1 Bromus and Koeleria response to microbial community structure.docx available at https://authorea.com/users/353394/articles/477310-saprotrophs-and-nitrifiers-notpathogens-drive-plant-soil-feedbacks-in-a-semi-arid-grassland

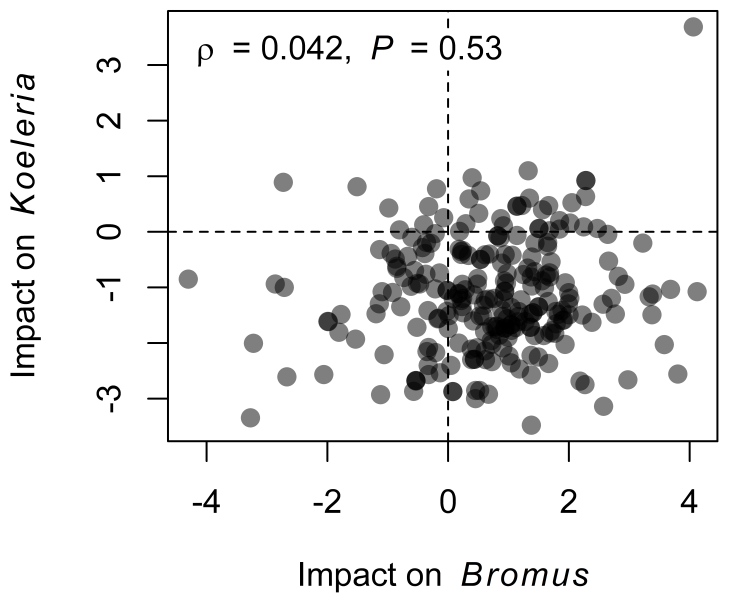

Figure 1

\section{Hosted file}

MAIN.pdf available at https://authorea.com/users/353394/articles/477310-saprotrophs-andnitrifiers-not-pathogens-drive-plant-soil-feedbacks-in-a-semi-arid-grassland 